\title{
Psychopathic traits and deception: functional magnetic resonance imaging study
}

Rachael S. Fullam, Shane McKie and Mairead C. Dolan

\section{Background}

There is relatively little existing information regarding the neural correlates of deception in individuals with psychopathic traits.

\begin{abstract}
Aims
To investigate the relationship between neural responses during deception and psychopathic personality traits in a sample of male participants drawn from the normal population.

\section{Method}

Twenty-four male participants carried out a simple deception paradigm while undergoing functional magnetic resonance imaging. Psychopathic traits were assessed in the sample using the Psychopathic Personality Inventory (PPI).
\end{abstract}

\section{Results}

Mean response times were greater for the lie than truth condition. Lie responses resulted in enhanced activation of the ventrolateral prefrontal cortex. The PPI sub-scales, coldheartedness, fearlessness, Machiavellian egocentricity, social potency and stress immunity were found to be correlated with activation patterns in the brain circuitry implicated in both deception and related processes such as behavioural restraint and social cognition.

\section{Conclusions}

This is a novel technology that may prove useful in our understanding of some of the key components of the psychopathy construct in both clinical and non-clinical contexts.

\section{Declaration of interest}

None. Funding detailed in Acknowledgements.
Deception is a normal component of human social interaction that follows a developmental trajectory. ${ }^{1}$ Disorders such as antisocial personality disorder and psychopathy, in particular, are characterised by high levels of deceptive behaviours and show a poor response to psychological treatment. ${ }^{2}$ Improving our ability to detect deceptive behaviours in forensic samples may help assist in the process of risk assessment and management of high-risk antisocial individuals. Although there are few studies explicitly investigating the relationship between psychopathy and deception, there is some evidence to suggest that psychopathy is not associated with an increased ability to deceive, but may be associated with alterations in the non-verbal correlates of deception. ${ }^{3}$ In recent years there has been a growth in interest in the use of functional magnetic imaging techniques (fMRI) to study the neural correlates of deception. In normal populations, fMRI neuroimaging studies of deception show activation in a variety of areas in the prefrontal cortex including the orbitofrontal/ventrolateral prefrontal cortex, ${ }^{1,4-10}$ and dorsolateral prefrontal cortex. $^{5-13}$ In addition, a number of other brain areas have been implicated in the neural control of deception including the anterior cingulate cortex ${ }^{11-14}$ thalamus, ${ }^{9,15}$ temporal lobes, ${ }^{12,14,15}$ parietal lobes, ${ }^{5,6,14,15}$ caudate $^{5,9}$ and insula. ${ }^{14,15}$ Recently, structural MRI studies have demonstrated increases in frontal white matter, ${ }^{16,17}$ particularly in the orbitofrontal lobes, ${ }^{17}$ in populations with marked deceitful traits as measured by the Psychopathy Checklist Revised (PCL-R). ${ }^{18}$ To date there is only one published fMRI study of deception that has included a measure of psychopathic personality traits. In an fMRI study of autobiographical and non-autobiographical deception in a mixed gender sample, Nunez et $a l^{9}$ found that higher coldheartedness scores on the Psychopathic Personality Inventory (PPI) ${ }^{19}$ were associated with reduced blood oxygen level dependent (BOLD) responses in the posterior cingulate and precuneus cortices, during non-autobiographical deception. However, psychopathic personality traits have been shown to be less frequent in female than male samples ${ }^{20,21}$ and the use of a mixed gender sample in the Nunez et al ${ }^{9}$ study may have attenuated the nature and type of associations found between brain activity during deception and psychopathic personality traits.

The aim of the present study was to use a simple fMRI deception paradigm devised by Spence et $a l^{4}$ to investigate the relationship between BOLD responses during deception and psychopathic personality traits measured using the PPI in a sample of male participants drawn from the normal population. Similar to Nunez et al, ${ }^{9}$ a lie was defined by the three basic features described by Coleman \& Kay. ${ }^{22}$ That is, the intentional giving of a false response and awareness that the response is false rather than a mistake. We predicted that consistent with the findings of previous studies using the same paradigm, ${ }^{1,4}$ deceitful responding (relative to truthful responding) would be associated with increased BOLD responses in the ventrolateral prefrontal cortex, and increased response times for false responses indicating an interference effect. We further predicted that scores on the PPI sub-scales would be significantly associated with BOLD responses in brain areas previously implicated in the neural control of deception.

\section{Method}

\section{Participants}

Twenty-four (21 right handed and 3 left handed) male participants aged $19-60$ years $($ mean $=30.04$, s.d. $=11.34)$ were recruited from University of Manchester ancillary staff and students. Specifically, participants were recruited using adverts placed in the University staff news letter and by approaching portering staff in each building. Students were recruited by targeting university sports teams (i.e. rugby teams) with the hypothesis that participants drawn from these populations may show higher levels of subclinical psychopathy spectrum personality traits. The majority 
( $n=22$ ) of the sample were White with the remaining participants of Asian ethnicity. The mean IQ of the sample measured using the National Adult Reading Test $^{23}$ was 113.87 (s.d. $=7.60$, range 96128). The study was approved by the University of Manchester research ethics committee and participants gave written informed consent for participation in the study.

\section{Measurement of psychopathic personality traits}

Psychopathic personality traits were assessed using the Psychopathic Personality Inventory. ${ }^{19}$ The PPI is a 187 -item self-report questionnaire with a total score and 8 sub-scales designed to measure psychopathic personality traits in a dimensional manner. These include:

(a) Machiavellian egocentricity which is characterised by 'looking out for one's own interests before others';

(b) social potency, or the 'ability to be charming and influence others';

(c) coldheartedness is the 'propensity towards callousness, guiltlessness, and unsentimentality';

(d) carefree non-planfulness, is the 'non-planning component of impulsivity';

(e) fearlessness, is the 'absence of anxiety and harm concerning eagerness to take risks';

(f) blame externalisation, is the 'tendency to view others as source of problems';

(g) impulsive non-conformity, is the 'reckless lack of concern for social mores';

(h) stress immunity, is the 'absence of marked reactions to otherwise anxiety provoking events' (pp. 500-2). ${ }^{19}$

Each item consists of a statement to which participants must indicate how accurately it applies to them using a 4-point scale ranging from 1 'false' to 4 'true'. The PPI has been shown to have good convergent and discriminant validity in both community and criminal samples. ${ }^{19,23-27}$ In particular, it shows good criterion related validity when compared with structured, collaboratively rated clinical assessments of psychopathy such as the PCL-R. ${ }^{18,24}$ The PPI scores for the sample are shown in Table 1. The mean total PPI score for the sample was lower than that reported by Lilienfeld et al (S. Lilienfeld, personal communication, 2008), for a large sample of substance misusing male prisoners (see online supplement for details). However, individuals in the present sample did show total scores at or above the criminal mean and the fearlessness, social potency, coldheartedness and stress immunity scores for the present sample were remarkably similar to those reported for the criminal population. Additional figures demonstrating the sample distribution of scores on each sub-scale can be found in the online Fig. DS1.

\section{Deception paradigm}

The deception task used in the present study was based on the task reported by Spence et al. ${ }^{4}$ Prior to scanning, participants were asked to fill in a questionnaire determining if they had performed 36 everyday acts during the current day (making the bed, taken a tablet, etc). Once in the scanner, participants were asked to lie or tell the truth about the performance of the 36 acts. In a standard $\mathrm{ABAB}$ block design, each participant was required to lie about the performance of each act once and tell the truth about the performance of each of the 36 acts once. Each of the 12 blocks contained 6 acts and each act was displayed visually on a screen for $5 \mathrm{~s}$ in the form 'In the course of today have you . . (made the bed)'. Participants were required to make a motor response on a button box in order to answer yes or no. They were instructed to lie or tell the truth depending on which prompt appeared on the screen. In order to increase task performance, participants were informed that an experimenter would be monitoring their responses in order to detect whether they were lying. Participants carried out a practice block prior to the main task. Response accuracy was calculated by comparing responses made to the truth or lie prompt during the task to the original response made in the 36-item questionnaire. Response times (seconds) were recorded for each trial and average response times during the truth and lie conditions were compared using a twotailed paired-sample $t$-test. In addition, response times and response accuracy (relative to the original questionnaire items) were correlated with PPI sub-scales using Spearman's correlations.

\section{MRI image acquisition}

Images were acquired using a Philips (Eindhoven, Holland) $1.5 \mathrm{~T}$ Gyroscan ACS NT retrofitted with Powertrak 6000 gradients, operating at a software level 6.1.2 $T_{2}{ }^{*}$-weighted volumes were acquired using a singleshot echo-planar imaging pulse sequence. Each volume comprised 40 contiguous axial slices, (response time (TR)/echo time (TE) $5000 / 40 \mathrm{~ms}, 64 \times 64$ data matrix, $3.5 \mathrm{~mm}$ thickness with an inplane resolution of $3 \times 3 \mathrm{~mm}$ ). The stimuli were rear projected onto a screen using a liquid crystal display projection system. Task administration was coupled to image acquisition using personal computer software and hardware linked to a response button.

\section{Analysis}

Imaging data were analysed using Statistical Parametric Mapping (SPM5, Friston, The Welcome Department of Cognitive Neurology, London, UK). Images were corrected for motion and then realigned with the first scan serving as a reference. The scans were then normalised into a standard stereotactic space ${ }^{28}$ using Montreal Neurological Institute templates. Images were finally smoothed with a $10 \mathrm{~mm}$ Gaussian filter to facilitate inter-individual averaging. After this spatial preprocessing, at an individual level, a general

\begin{tabular}{|c|c|c|c|c|}
\hline & Items, $n$ & Mean & s.d. & Range \\
\hline Total score & 163 & 364.71 & 35.03 & $313.00-442.00$ \\
\hline Machiavellian egocentricity & 30 & 61.75 & 10.78 & $46.00-84.00$ \\
\hline Social potency & 24 & 64.08 & 10.01 & $46.00-79.00$ \\
\hline Fearlessness & 19 & 49.42 & 8.92 & $34.00-66.00$ \\
\hline Coldheartedness & 21 & 45.50 & 7.32 & $36.00-59.00$ \\
\hline Impulsive non-conformity & 17 & 36.70 & 7.75 & $24.00-54.00$ \\
\hline Blame externalisation & 18 & 31.58 & 7.91 & $19.00-51.00$ \\
\hline Carefree non-planfulness & 20 & 37.79 & 6.78 & $26.00-50.00$ \\
\hline Stress immunity & 11 & 31.75 & 5.36 & $17.00-39.00$ \\
\hline
\end{tabular}


linear model with a delayed boxcar waveform was used to model BOLD signal changes during the task. The individual images were then combined in a random effects analysis that would allow inference to the general population using an independent samples $t$-test to investigate the main effect of the task. The main effect for the lie condition was the BOLD signal seen in the lie condition minus the BOLD signal seen in the truth condition. The main effect for the truth condition was the reverse subtraction.

The resulting statistical maps were thresholded at $P<0.001$ uncorrected with only cluster sizes of five or more contiguous voxels being reported. As the inferior (frontopolar/orbitofrontal/ ventrolateral prefrontal), and superior frontal (dorsolateral/ dorsomedial prefrontal) cortex are the regions in which activations are most consistently reported across different deception paradigms in the literature, we concentrated our primary analysis solely on these areas. In order to control for type I errors we applied small volume corrections ${ }^{29}$ for family-wise error at $P \leqslant 0.05$ to these a priori regions of interest. Areas of activation at the $P<0.001$ uncorrected level are also reported when bilateral activations were seen.

In addition, we performed an exploratory analysis of signal in those areas less consistently identified by the past literature as active during deceptive responses; anterior cingulate, caudate, insula, thalamus, temporal lobes, temporal poles, posterior cingulate and precuneus. Again, in these regions we performed small volume corrections for family-wise error.

The association between BOLD responses during the lie condition and scores on the PPI sub-scales was investigated using simple regression analysis. During this analysis, for each a priori specified brain area of interest that exhibited a significant voxelbased correlation, the BOLD signal change observed during the lie condition was extracted from SPM and used in Spearman's correlational analysis (SPSS version 14 for Windows) in order to produce confirmatory $r$-values. As a further protection against type I errors we have only reported results where the probability value of the associated $r$-value exceeded $P \leqslant 0.001$ for unilateral activations and $P \leqslant 0.01$ for bilateral activations.

Finally, in order to control for possible within-sample variation in age, we examined the correlation between age and BOLD responses during the deception condition. Age was found to be positively correlated with BOLD response in the temporal poles and insula and was therefore entered as a nuisance covariate in any analyses where significant BOLD responses were exhibited in these areas.

\section{Results}

\section{Behavioural data}

Mean response accuracy was similar for the truth (91.06\%, s.d.=11.66) and lie condition $(91.55 \%$, s.d. $=12.21)$. The number of accurate responses (maximum of 36) for the lie condition showed a significant positive correlation with PPI stress immunity score $(r=0.53, P=0.009)$.

Mean response times (seconds) were significantly slower during the lie condition compared with the truth condition (lie mean response time $2.66 \mathrm{~s}$ (s.d. $=0.42$ ), truth mean response time 2.56 s (s.d. $=0.39$ ); $t=2.43, P=0.024$ ).

There were no significant correlations between any of the other mean PPI sub-scales/factor scores and mean response accuracy or response time for the lie condition or truth condition.

\section{Functional MRI data}

\section{Main effect of task}

During the lie condition (relative to the truth condition) an increased BOLD response was seen in the left ventrolateral prefrontal cortex (Brodmann area (BA)47). An increased BOLD response at the $P<0.001$ uncorrected level was also seen in the right ventrolateral prefrontal cortex (Table 2 and online Fig. DS2).

During the truth condition (relative to the lie condition) an increased BOLD response was seen bilaterally in the frontopolar area of the prefrontal cortex (BA10) extending into the medial superior frontal cortex (Table 2).

The results remained similar when the analysis was rerun excluding six participants who achieved less than $90 \%$ overall response accuracy for the task.

\section{Relationship between the PPI sub-scales and BOLD response during the lie condition}

The results of the correlational analysis are shown in Table 3. During the lie condition (relative to the truth), fearlessness scores were negatively correlated with BOLD responses in the right orbitofrontal cortex (Fig. 1). Coldheartedness scores were negatively correlated with BOLD responses bilaterally in the temporal poles (Fig. 2). Machiavellian egocentricity scores were negatively correlated with BOLD responses bilaterally in the caudate. Social potency scores were negatively correlated with BOLD responses bilaterally in the right posterior cingulate. Stress immunity scores were negatively correlated with BOLD response bilaterally in the insula. These associations remained significant after covarying for handedness and age (where appropriate).

There were no significant associations between BOLD responses during the lie condition in any of the brain areas of interest and the PPI total score or impulsive non-conformity, carefree non-planfullness and blame externalisation sub-scale scores.

\section{Discussion}

The ability to non-invasively examine the neural correlates of deception in disorders such as antisocial personality disorder

\begin{tabular}{|c|c|c|c|c|c|}
\hline Cluster size $(\mathrm{k})$ & $\begin{array}{c}\text { Montreal Neurological } \\
\text { Institute coordinates } \\
x, y, z\end{array}$ & $Z$ & $\begin{array}{l}\text { Family-wise error, } \\
\text { corrected probability }\end{array}$ & Anatomical area & Brodmann area \\
\hline \multicolumn{6}{|l|}{ Lie-truth } \\
\hline 42 & $-30,24,-12$ & 4.27 & 0.004 & Left ventrolateral prefrontal cortex & 47 \\
\hline 42 & $51,24,-15$ & 3.24 & $0.105^{a}$ & Right ventrolateral prefrontal cortex & 47 \\
\hline \multicolumn{6}{|l|}{ Truth-lie } \\
\hline 34 & $-6,48,-6$ & 4.39 & 0.001 & Left frontopolar prefrontal cortex & 10 \\
\hline 20 & $3,48,-3$ & 3.48 & 0.024 & Right frontopolar prefrontal cortex & 10 \\
\hline 28 & $-9,54,0$ & 3.85 & 0.030 & Left medial superior frontal & 10 \\
\hline 25 & $6,51,0$ & 3.29 & $0.088^{a}$ & Right medial superior frontal & 10 \\
\hline
\end{tabular}




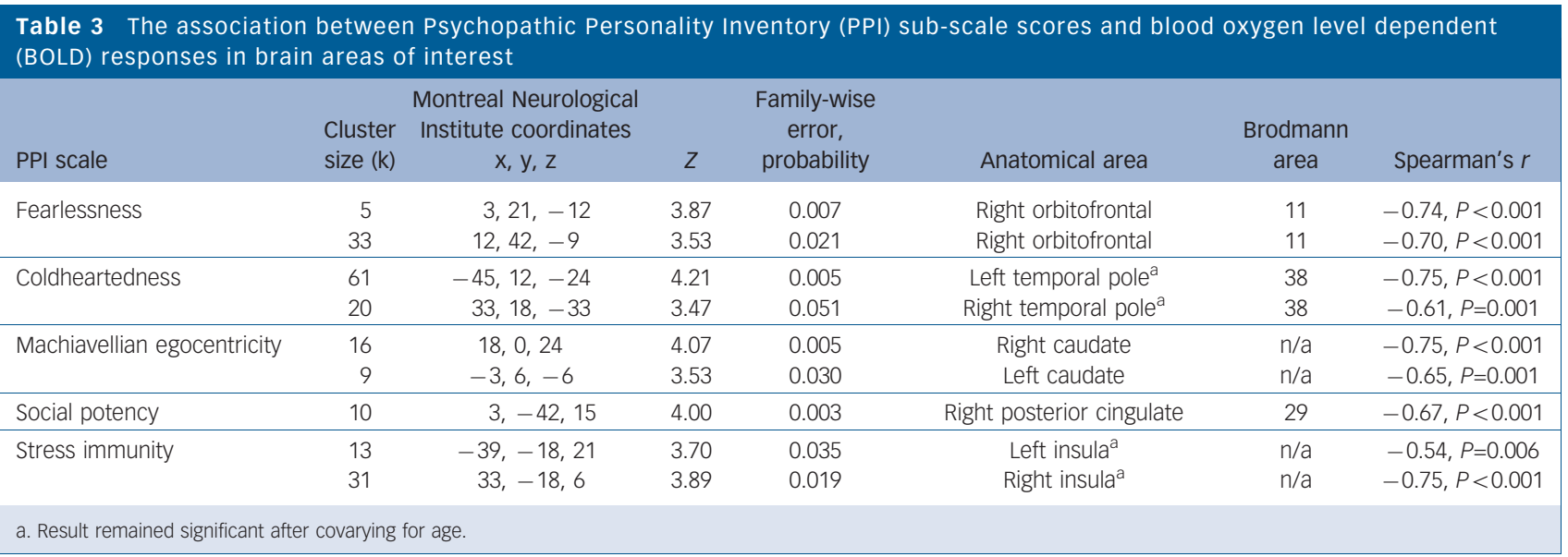

and psychopathy, where deception is prominent, could offer new insights into the neuropathology of these disorders. Despite the range of paradigms and scanning parameters used, BOLD fMRI studies in healthy volunteers suggest that the prefrontal cortex, anterior cingulate cortex, temporal and parietal lobes, and a number of subcortical areas are involved in the neural control of deception. ${ }^{1,4-15}$ Few studies have specifically looked at the role of psychopathic personality traits despite one report that callous unemotional traits may be associated with reduced activation in brain regions required for deceptive behaviours that have no personal significance. ${ }^{9}$ This study examined the relationship between psychopathic personality trait scores and BOLD responses in brain areas of interest during a simple deception task devised by Spence et al ${ }^{4}$ in male participants drawn from the normal population.

\section{Behavioural data}

Consistent with previous studies in this field ${ }^{4,9}$ we found that the behavioural data indicated that mean response times were significantly longer for the lie compared with the truth condition but there was no effect of personality trait scores. It is possible that the relatively small sample size may account for the lack of an observed association between response time and personality traits. However, Nunez et $a l^{9}$ also failed to find an association between

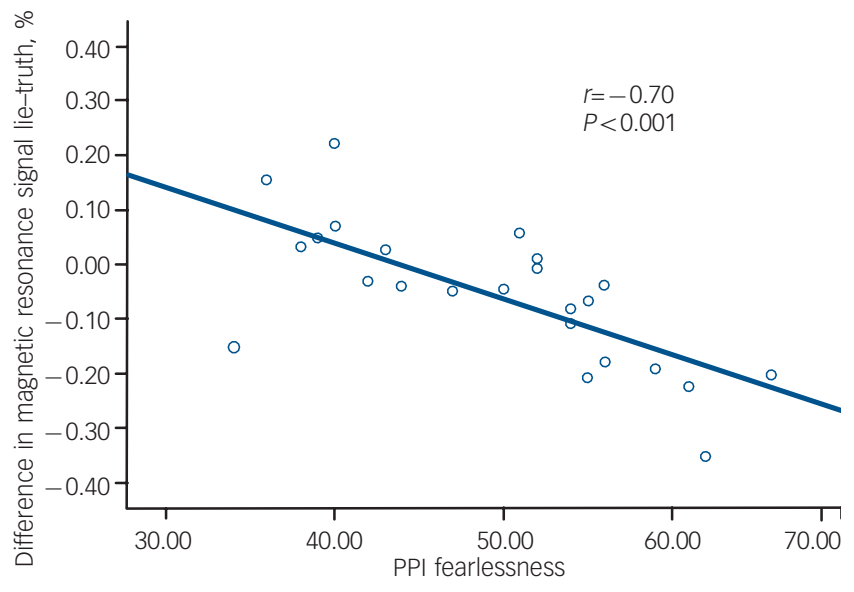

Fig. 1 The association between Psychopathic Personality Inventory (PPI) fearlessness and blood oxygen level dependent response in the right orbitofrontal cortex during deception. response times during lie responses and scores on the PPI. We did find, however, that stress immunity, which reflects a lack of anxiety, was positively correlated with response accuracy in the lie condition. This would support the argument that interpersonal differences in trait anxiety can mediate behavioural and physiological responses during deception..$^{30,31}$ This is an area that may warrant further investigation in imaging studies of deception.

\section{Main effect of task imaging data}

Consistent with our hypothesis, we found that the lie condition (relative to the truth condition) was associated with increased BOLD responses bilaterally in the ventrolateral prefrontal cortex. This is a replication of the finding reported by Spence et al ${ }^{4}$ using the same task in a smaller sample, and as such represents the first between-laboratory replication of an fMRI deception finding (a research gap recently highlighted by Spence ${ }^{32}$ ). This finding also supports previous studies using different deception paradigms that have reported deception related BOLD responses in inferior frontal areas. ${ }^{6,8,9,14}$ As the ventrolateral prefrontal cortex has been shown to be active during a number of cognitive control paradigms $^{33-36}$ this finding also adds further weight to the argument that deception engages executive prefrontal systems in order to achieve the production of a 'lie' at the same time as withholding the truth. ${ }^{1,4}$ Similar to Spence et al ${ }^{4}$ we did not find any significant BOLD responses during deception in any of the

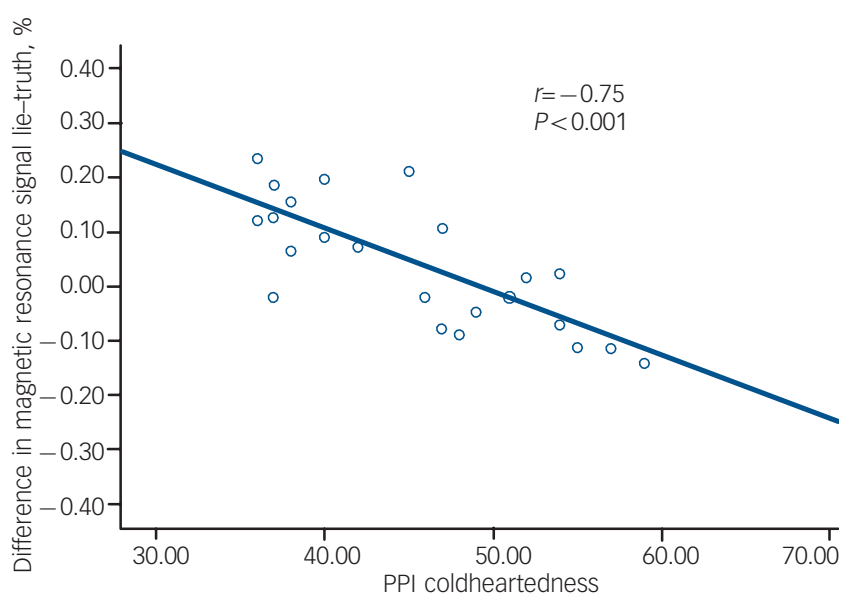

Fig. 2 The association between Psychopathic Personality Inventory (PPI) coldheartedness and blood oxygen level dependent response in the temporal poles during deception. 
other frontal areas of interest. Given that previous studies in the area $^{4-13}$ have shown deception-related activity in the dorsolateral prefrontal cortex and orbitofrontal cortex, it is possible that between-study deception paradigm and sample size differences may account for the current lack of findings in these areas.

We also found that the truth condition was associated with increased BOLD responses bilaterally in the frontopolar cortex. In a recent review of frontopolar function, Koechlin et $a l^{37}$ suggest that during decision-making tasks, lateral inferior frontal regions inhibit frontopolar regions in order to switch to and maintain a given response set. They also propose that frontopolar regions are able to store a previous response set in a back-up buffer in order to reinstate it following a reduction in top-down inhibition. In the present study, during the lie condition, the lateral inferior frontal cortex may have been exerting a strong inhibitory influence on the frontopolar regions in order to override the alternative truthful response set and switch to the deceitful set. In the truth condition, the frontopolar regions may have shown enhanced activation while accessing and returning to the use of the truthful response set. It is possible, therefore, that the underlying 'task-switching' nature of the deception paradigm used in the current study may be largely responsible for the activations seen during the truth condition. The majority of published studies in this area do not specifically examine BOLD responses during the truthful condition; however, of those that do, few reported any areas of activation during truthful responding. ${ }^{1,8-10}$ Despite these negative findings, Langleben et $a l^{7}$ reported truth-related activations in the left medial frontal gyrus (BA46). The differences in findings may not only reflect inter-study differences in methodology, but also, in this case in particular, inter-laboratory differences in the ability to accurately image the frontopolar region without a large degree of airspace related signal drop out.

\section{Relationship between personality factors and imaging findings}

Psychopathy as a construct is generally considered to be characterised by high levels of callous unemotional traits and these traits are believed to be related to dysfunction in the limbic (amygdala) striatal prefrontal circuitry. ${ }^{38}$ The ability to measure key components of the psychopathy construct in less pathological samples allows us to postulate on the potential neuropathology of this disorder in clinical samples. The present study found evidence that BOLD responses during deception in a number of brain areas of interest were correlated with some, but not all, psychopathic personality trait scores. Specifically focusing on the prefrontal cortex, we found inverse correlations between fearlessness scores and BOLD responses in the right orbitofrontal lobe. This suggests that those with low levels of fear and harm avoidance may find it easier to lie and therefore do not activate the orbitofrontal cortex which is a key neural structure implicated in behavioural inhibition in a number of previous imaging studies. ${ }^{33,39}$ Our own work on the neuropsychology of behavioural inhibition in samples of offenders with antisocial personality disorder suggests that this clinical group are significantly impaired on tasks probing orbitofrontal cortex function compared with healthy controls. ${ }^{40}$ Given reports of increased white matter volume in some of the prefrontal subregions implicated in deception-related neurocircuitry in those who lie, cheat and manipulate others, ${ }^{16,17}$ this is a brain area that warrants more detailed investigation.

In our exploratory analysis, we found that coldheartedness was inversely correlated with temporal pole BOLD responses. As the temporal pole has been found to be active during theory of mind tasks, ${ }^{41}$ our findings highlight the importance of looking at the role of callous unemotional traits and theory of mind/ mentalising ability in tasks assessing the cognitive elements that may be involved in the deception and manipulation of others. Nunez et $a l^{9}$ found that coldheartedness assessed using the PPI was negatively correlated with BOLD responses in the posterior cingulate and precuneus cortices. In the present study, BOLD signal in the posterior cingulate was inversely associated with PPI social potency scores. Differences between studies may reflect the gender differences in the nature of the samples studied. Base rates of psychopathic traits are lower in female populations, ${ }^{42}$ and female populations exhibit lower scores on some (but not all) specific symptoms such as callousness/lack of empathy on the PCL-R, ${ }^{42}$ PPI stress immunity, PPI social potency and on a factor similar to PPI coldheartedness. ${ }^{43}$ In addition, there is some indication of a gender difference in the bio-behavioural correlates of psychopathy, with only male cohorts exhibiting a lack of physiological reactivity to aversive stimuli ${ }^{44}$ and stress. ${ }^{45}$

In this study we also found that lower stress immunity scores (i.e. more anxiety/stress) were associated with greater BOLD responses in the bilateral insula. As the insula has been shown to be involved in error processing during Go/No Go tasks, ${ }^{46}$ it is possible that stress immunity (which may relate to vigilance) may influence the function of the neural circuitry involved in the processing and monitoring of errors. Although at least some degree of anxiety is needed to engage error processing circuitry appropriately, it is possible that high levels may impair accuracy performance on behavioural tasks and moderate neural responses in imaging studies. Further studies are required to investigate the significance of both trait and state anxiety in deception-related brain activation patterns in those with antisocial and deceptive personality traits.

We found that higher Machiavellian egocentricity scores were associated with reduced BOLD responses in the bilateral caudate. Although there is a limited literature to compare the findings of the present study, decreased caudate activity appears to be associated with higher scores on the interpersonal (deceptive/ superficial/grandiose) component of psychopathy, ${ }^{47}$ indicating that people with these and related personality traits, such as Machiavellian egocentricity, show reduced activation of caudate regions which are a key component of the subcortical straital network. A common finding across species and methodologies is the involvement of the striatum, the input structure of the basal ganglia, in a circuit responsible for mediating goal-directed behaviour. ${ }^{48}$ In functional imaging studies, the caudate has been shown to be involved in the inhibition of both motor and mental responses $^{49-55}$ and appears to be specifically involved in the mediation of arousal. ${ }^{56}$

Overall, our findings fit with the previous literature suggesting that simple deception tasks activate prefrontal regions implicated in behavioural restraint and conflict monitoring and that lying results in greater activation than truthful responding. Our findings also tentatively suggest that specific personality traits may have a modulating effect on brain responses to deception tasks and that future studies examining brain activation during deception in offenders with and without psychopathic traits may be of value in understanding the neuropathology of psychopathy and antisocial personality disorder.

\section{Limitations}

Although the results of the present study are suggestive of an association between psychopathic traits and the neural processes involved in deception, there are a number of limitations that need to be taken into consideration. The deception paradigm used is highly constrained and similar in terms of cognitive demands to a Go/No Go test of behavioural inhibition. Recent imaging studies 
of deception are utilising more complex ecologically valid paradigms. For example, a recent study by Abe et $a l^{13}$ has demonstrated the involvement of the amygdala in a deception paradigm with a social component and it is possible that this neural response may also show some relationship with the callous/unemotional aspects of psychopathy. In addition, the use of the PPI in the present study may have limited the measurement of the core deceitful/manipulative components of psychopathy. The majority of the PPI items focus on impulsive/antisocial or fearless/dominant traits, ${ }^{26}$ a more selective use of multiple measures of deception, such as those used by Yang et al, ${ }^{16,17}$ may have produced more specific neural correlates of a deceitful personality type.

Rachael S. Fullam, PhD, Centre for Forensic Behavioural Science, Monash University, and the Victorian Institute of Forensic Mental Health, Melbourne, Australia Shane McKie, PhD, University of Manchester, UK; Mairead C. Dolan, MRCPsych, $\mathrm{PhD}$, Centre for Forensic Behavioural Science, Monash University, and the Victorian Institute of Forensic Mental Health, Melbourne, Australia.

Correspondence: Rachael Fullam, Centre for Forensic Behavioural Science, School of Psychology, Psychiatry and Psychological Medicine, Monash University, Victorian Institute of Forensic Mental Health, Locked Bag 10, Fairfield VIC 3078, Australia. Email: rachael.fullam@forensicare.vic.gov.au

First received 31 Mar 2008, final revision 22 Jul 2008, accepted 24 Sep 2008

\section{Acknowledgements}

This work was supported by an award of free MRI scanning time given by the Translationa Imaging Unit, Faculty of Medical and Human Sciences, University of Manchester, UK.

\section{References}

1 Spence SA, Hunter MD, Farrow FD, Green RD, Leung DH, Hughes $\mathrm{CJ}$, et al. A cognitive neurobiological account of deception: evidence from functional neuroimaging. Philos Trans R Soc Lond B Biol Sci 2004; 359: 1755-62.

2 Hare RD. Psychopathy, affect and behaviour. In Psychopathy: Theory, Research and Implications for Society (eds DJ Cooke, AE Forth): 106-137. Kluwer Academic Publishers, 1998.

3 Klaver JR, Lee Z, Hard SD. Psychopathy and non verbal indicators of deception in offenders. Law Hum Behav 2007; 31: 337-51.

4 Spence SA, Farrow TD, Herford AE, Wilkinson ID, Zheng Y Woodruff PWR. Behavioural and functional anatomical correlates of deception in humans. Neuroreport 2001; 12: 2849-53.

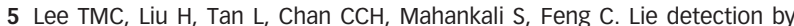
functional magnetic resonance imaging. Hum Brain Mapp 2002; 15: 157-64.

6 Lee TMC, Ho-Ling L, Chan CCH, Yen-Bee Ng, Fox PT, Gao J. Neural correlates of feigned memory impairment. Neuroimage 2005; 28: 305-13.

7 Langleben DD, Loughead JW, Bilker WB, Ruparel K, Childress AR, Busch SI, et al. Telling truth from lie in individual subjects with fast event related fMRI. Hum Brain Mapp 2005; 26: 262-72.

8 Luan Phan K, Magalhaes A, Ziemlewicz TJ, Fitzgerald DA, Green C, Smith W. Neural correlates of telling lies: a functional magnetic resonance imaging study at 4 tesla. Acad Radiol 2005; 12: 164-72.

9 Nunez MJ, Casey BJ, Egner T, Hare T, Hirsch J. Intentional false responding shares neural substrates with response conflict and control. Neuroimage 2005; 25: 267-77.

10 Kozel FA, Padgett TM, George MS. A replication study of the neural correlates of deception. Behav Neurosci 2004; 118: 852-6.

11 Ganis G, Kosslyn SM, Stose S, Thompson WL, Yurgelun-Todd DA. Neural correlates of different types of deception: an fMRI investigation. Cereb Cortex 2003; 13: 830-6.

12 Kozel FA, Padgett TM, George MS. A replication study of the neural correlates of deception. Behav Neurosci 2004; 118: 852-6.

13 Abe N, Suzuki M, Mori E, Itoh M, Fujii T. Deceiving others: distinct neural responses of the prefrontal cortex and amygdala in simple fabrication and deception with social interactions. J Cogn Neurosci 2007; 19: 287-95.

14 Langleben DD, Schroeder L, Maldjian JA, Gur RC, McDonald S, Ragland JD, et al. Brain activity during stimulated deception: an event related magnetic resonance study. Neuroimage 2002; 15: 727-32.
15 Kozel AF, Johnson KA, Mu Q, Grenesko EL, Laken SJ George MS. Detecting deception using functional magnetic resonance imaging. Biol Psychiatry 2005; 58: 605-13.

16 Yang Y, Raine A, Lencz T, Bihrle S, Lacasse L, Colletti P. Prefrontal white matter in pathological liars. Br J Psychiatry 2005; 187: 320-5.

17 Yang $Y$, Raine A, Narr KL, Lencz T, LaCasse L, Colletti $P$, et al. Localisation of increased prefrontal white matter in pathological liars. Br J Psychiatry 2007; 190: $174-5$.

18 Hare RD. The Psychopathy Checklist-Revised (PCL-R). Multi Health Systems Inc, 1991.

19 Lilienfeld SO, Andrews BP. Development and preliminary validation of a self report measure of psychopathic personality traits in noncriminal populations. J Pers Assess 1996; 66: 488-524.

20 Salekin RT, Rogers R, Sewell KW. Construct validity of psychopathy in a female offender sample: a multitrait-multimethod evaluation. J Abnorm Psychol 1997; 106: 576-85.

21 Salekin RT, Rogers R, Ustad KL, Sewell KW. Psychopathy and recidivism among female inmates. Law Hum Behav 1998; 22: 109-28.

22 Coleman L, Kay P. Prototype semantics: the English word lie. Language 1981; 57: $26-44$.

23 Nelson H. National Adult Reading Test Manual. nferNelson, 1991.

24 Poythress NG, Edens JF, Lilienfeld So. Criterion-related validity of the Psychopathic Personality Inventory in a prison sample. Psychol Assess 1998; 10: 426-30.

25 Sandoval A, Hancock D, Poythress NG, Edens J F, Lilienfeld SO. Construct validity of the Psychopathic Personality Inventory in a correctional sample. J Pers Assess 2000; 74: 262-81.

26 Benning SD, Patrick CJ, Hicks BM, Blonigen DM, Krueger RF. Factor structure of the Psychopathic Personality Inventory: validity and implications for clinical assessment. Psychol Assess 2003; 15: 340-50.

27 Patrick CJ, Edens JF, Poythress NG, Lilienfeld SO Benning SD. Construct validity of the Psychopathic Personality Inventory two factor model with offenders. Psychol Assess 2006; 18: 204-8.

28 Talairach J, Tournoux P. Co-planar Stereotaxic Atlas of the Human Brain 3-Dimensional Proportional System. An Approach to Cerebral Imaging. Thieme Medical, 1988

29 Worsley KJ, Marrett S, Neelin P, Vandai AC, Friston KJ, Evans AC. A unified statistical approach for determining significant signals in images of cerebral activation. Hum Brain Mapp 1996; 4: 58-73.

30 Wiley SD. Deception and detection in psychiatric disgnosis. Psychiatr Clin North Am 1998; 21: 869-93.

31 Steinbrook R. The polygraph test: a flawed diagnostic method. N Engl J Med 1992; 327: 122-3.

32 Spence SA. Playing Devil's advocate: the case against fMRI lie detection. Legal and Criminological Psychology 2008; 13: 11-25.

33 Ridderinkhof KR, van den Wildenberg WP, Segalowitz SJ, Carter CS. Neurocognitive mechanisms of cognitive control: the role of prefrontal cortex in action selection, response inhibition, performance monitoring, and rewardbased learning. Brain Cogn 2004; 56: 129-40.

34 Blasi G, Goldberg TE, Weickert T, Das S, Kohn P, Zoltick B, et al. Brain regions underlying response inhibition and interference monitoring and suppression. Eur J Neurosci 2006; 23: 1658-64.

35 Lie $\mathrm{CH}$, Specht K, Marshall JC, Fink GR. Using fMRI to decompose the neural processes underlying the Wisconsin Card Sorting Test. Neuroimage 2006; 30 : 1038-49.

36 Dove A, Manly T, Epstein R, Owen AM. The engagement of mid-ventrolateral prefrontal cortex and posterior brain regions in intentional cognitive activity. Hum Brain Mapp 2008; 29: 107-19.

37 Koechlin E, Hyafil A. Anterior prefrontal function and the limits of human decision-making. Science 2007; 318: 594-8.

38 Blair RJR. Applying a cognitive neuroscience perspective to the disorder of psychopathy. Dev Psychopathol 2005; 17: 865-91.

39 Horn N, Dolan M, Elliot R, Deakin JFW, Woodruff. PW. Response inhibition and impulsivity: an FMRI study. Neuropsychologia 2003; 41: 1959-66.

40 Dolan M, Park I. The neuropsychology of antisocial personality disorder. Psychol Med 2002; 32: 417-27.

41 Olson IR, Plotzker A, Ezzyat Y. The Enigmatic temporal pole: a review of findings on social and emotional processing. Brain 2007; 130: 1718-31.

42 Grann M. The PCL-R and gender. Eur J Psychol Assess 2000; 16: 147-9.

43 Maesschalck C, Vertommen $\mathrm{H}$, Hooghe A. Psychometric characteristics of the Psychopathic Personality Inventory in a Dutch-speaking population. Int J Testing 2002; 2: 169-98. 
44 Justus AN, Finn PR. Startle modulation in non-incarcerated men and women with psychopathic traits. Pers Individ Dif 2007; 43: 2057-71.

45 O'Leary MM, Loney BR, Eckel LA. Gender differences in the association between psychopathic personality traits and cortisol response to induced stress. Psychoneuroendocrinology 2007; 32: 183-91.

46 Hester R, Fassbender C, Garavan H. Individual differences in error processing: a review and reanalysis of three event-related $\mathrm{fMRI}$ studies using the GO/NO GO task. Cereb Cortex 2004; 14: 986-94.

47 Soderstrom $\mathrm{H}$, Hultin L, Tullberg M, Wikkelso C, Ekholm S, Forsman A. Reduced frontotemporalperfusion in psychopathic personality. Psychiatry Res 2002; 114: 81-94.

48 Delgado MR. Rewardrelated responses in the human striatum. Ann N Y Acad Sci 2007; 1104: 70-88.

49 Mink JW. The basal ganglia: focused selection and inhibition of competing motor programs. Prog Neurobiol 1996; 50: 381-425.

50 Redgrave P, Prescott TJ, Gurney K. The basal ganglia: a vertebrate solution to the selection problem. Neuroscience 1999; 89: 1009-23.
51 Casey BJ, Forman SD, Franzen P, Berkowitz A, Braver TS, Nystrom LE, et al. Sensitivity of prefrontal cortex to changes in target probability: a functional MRI study. Hum Brain Mapp 2001; 13: 26-33.

52 Casey BJ, Thomas KM, Davidson MC, Kunz K, Franzen PL. Dissociating striatal and hippocampal function developmentally with a stimulusresponse compatibility task. J Neurosci 2002; 22: 8647-52.

53 Peterson BS, Kane MJ, Alexander GM, Lacadie C, Skudlarski P, Leung HC, et al. An event-related functional MRI study comparing interference effects in the Simon and Stroop tasks. Brain Res 2002; 13: 427-40.

54 Durston S, Thomas KM, Worden MS, Yang Y, Casey BJ. The effect of preceding context on inhibition: an event-related fMRI study. Neurolmage 2002; 16: 449-53.

55 Durston S, Davidson MC, Thomas KM, Worden MS, Tottenham N, Martinez A, et al. Parametric manipulation of conflict and response competition using rapid mixed trial event-related fMRI. Neurolmage 2003; 20: 2135-41.

56 Brown SM, Manuck SB, Flory JD, Hariri AR. Neural basis of individual differences in impulsivity: contributions of corticolimbic circuits for behavioural arousal and control. Emotion 2006; 6: 239-45.

कि EXTRA

\title{
The Bipolar World Within Us
}

\author{
Jenny Wells
}

Love and hate, generous and greedy

Kind and cruel, independent and needy

Lead and follow, good and bad

Release and hold, happy and sad

Optimist and pessimist, high and low

Child and adult, yes and no

Honest and dishonest, weak and strong

Content and jealous, right and wrong

Help and hinder, shallow and deep

Silent and loud, sow and reap

Healthy and ill, busy and lazy

Certain and doubt, sane and crazy

Laugh and cry, fall and rise

Sweet and bitter, ignorant and wise

Passive and aggressive, cool and warm

Give and take, calm and storm

Feminine and masculine, joy and pain

Saint and sinner, modest and vain

Clever and foolish, slow and fast

Change and stagnate, fail and pass

Teacher and student, young and old

courage and fear, shy and bold.

Born in Kent, I spent most of my early life in Aberystwyth and now live in Cornwall with my husband and our son. I was diagnosed with bipolar disorder in 1994 at the age of 33. It was very confusing, especially for my family, as I was manic and oblivious. I was heavily medicated for nearly 2 years, which made me emotionally numb, and I had been admitted to psychiatric hospitals three times, last time in 1997. I have had many episodes since, though I learnt to control the illness to some extent and I rarely have lows, mostly highs. Many positive things have happened since my diagnosis - I now work for a local mental health charity, helping to eradicate the stigma associated with mental ill health; I hope that my poems are a way of doing this also. 